\title{
Protective activity of a murine monoclonal antibody against acute and chronic experimental infection with type IV group B streptococcus
}

\author{
M. LUISA RICCI, CHRISTINA VON HUNOLSTEIN, MARIA J. GOMEZ, LAURA PARISI, \\ LUCIANA TISSI* and GRAZIELLA OREFICI†
}

Laboratory of Bacteriology and Medical Mycology, Istituto Superiore di Sanità, Rome and * Microbiology

Section, Department of Experimental Medicine and Biochemical Sciences, University of Perugia, Perugia, Italy

\begin{abstract}
A murine IgM monoclonal antibody (MAb H11) was developed against the type polysaccharide capsular antigen of group B streptococcus (GBS), serotype IV, after intraperitoneal immunisation of BALB/c mice with heat-killed bacteria. MAb H11 reacted in immunodiffusion with the purified polysaccharide in both its sialylated and desialylated form, giving a line of identity, and opsonised type IV GBS strains in an invitro assay. When administered at the time of intraperitoneal lethal challenge with homologous GBS, or $4 \mathrm{~h}$ earlier, MAb H11 protected $90 \%$ of the mice. Protection was still observed when MAb H11 was given $4 \mathrm{~h}$ after the challenge. This MAb was strongly effective in preventing septic arthritis induced by type IV GBS.
\end{abstract}

\section{Introduction}

Streptococcus agalactiae (group B streptococcus; GBS) infection is a life-threatening neonatal disease [1], and there is also evidence of its role in severe adult invasive disease [2, 3]. Clinical features of GBS infection include endocarditis, osteomyelitis, septic arthritis and endophthalmitis. The capsule of GBS is an important virulence factor in systemic disease [4], and antibodies that react with the type capsular antigens are protective in neonatal infections [5]. For this reason, some authors support the use of immunotherapy in GBS infections [6] and intravenous (i.v.) administration of immunoglobulins is effective not only in animal models but also in experimental trials in man [7-9]. Moreover, human and murine monoclonal antibodies (MAb) against type or group B polysaccharide (common to all GBS strains) provide protection in animal models of acute systemic GBS infection [10-15]. A murine model of chronic GBS infection with septic arthritis caused by type IV GBS [16], a serotype not frequently isolated but responsible for human invasive disease, has been described $[17,18]$. As with other GBS serotypes, type IV GBS has a typespecific polysaccharide antigen composed of repeated subunits of glucose, galactose, $\mathrm{N}$-acetylglucosamine and sialic acid [19]; this forms a thin and irregularly shaped capsule [20].

Received 24 Oct. 1995; accepted 29 Oct. 1995.

†Corresponding author: Dr G. Orefici.
To our knowledge, no MAb against type IV polysaccharide has been produced, so this study investigated the protective role of type-specific antibodies in acute and chronic experimental infections with type IV GBS, with MAb produced against the type IV polysaccharide antigen. The immunological and functional characteristics of the selected anti-type IV monoclonal antibody (MAb H11) are described and the efficacy of MAb H11 is compared with rabbit hyperimmune anti-group B and anti-type IV serum.

\section{Materials and methods}

\section{Bacterial strains, antigens and antisera}

Type IV GBS, reference strain $1 / 82$, was kindly supplied by Dr J. Jelinkova (National Public Health Institute, Prague, Czech Republic). Additional type IV strains (nos 1606 and 1613), isolated from the urine of diabetic patients, were also used. Other GBS strains were O90 (type Ia), NCTC 8187 (type Ib), NCTC 11079 (type II), NCTC 11080 (type III) (kindly supplied by Dr G. Colman, Central Public Health Laboratory, 61 Colindale Avenue, London) and strain 10/84 (type V) (from Dr J. Jelinkova).

All strains were stored at $-80^{\circ} \mathrm{C}$ in Todd-Hewitt Broth (THB; Unipath) containing sheep blood $10 \% \mathrm{v} / \mathrm{v}$. Frozen cultures were streaked on to sheep blood 5\% v/v Columbia agar plates (Unipath) and incubated at $37^{\circ} \mathrm{C}$ overnight. For experimental infections, the organisms were grown to the stationary phase $(18 \mathrm{~h})$ 
in THB at $37^{\circ} \mathrm{C}$, washed and diluted in serum-free RPMI 1640 medium (Flow Laboratories, McLean, VA, USA). The inoculum size was estimated turbidimetrically at $540 \mathrm{~nm}$ and the number of live bacteria was calculated by enumeration of colony-forming units (cfu) on sheep blood 5\% v/v Columbia agar plates. Polysaccharides of all group B serotypes and group polysaccharide were produced and purified as described previously [21].

Group- and type-specific GBS antisera were raised in rabbits immunised with formalin-killed whole bacterial cells, as described by Lancefield [22]. Serum titres were determined by ELISA [21]. These were 64000 and 32000 for anti-typeIV GBS and anti-group B serum, respectively.

\section{Mice}

BALB/c and CD1 mice were purchased from Charles River Breeding Laboratories, Calco, Milan, Italy.

\section{Murine monoclonal antibodies}

BALB/c female mice (2 months old) were immunised intraperitoneally (i.p.) with $0.2 \mathrm{ml}$ of an overnight culture of a heat-inactivated cell suspension of type IV GBS, strain 1/82 $\left(\mathrm{OD}_{590}, 0.6\right.$ : corresponding to $10^{8} \mathrm{cfu} /$ $\mathrm{ml})$. Booster injections were administered on day 7 $(0.1 \mathrm{ml}$ of vaccine, i.v.), day $14(0.1 \mathrm{ml}$ i.p. $)$ and day $130(0.1 \mathrm{ml}$ i.p. and $0.2 \mathrm{ml}$ i.v.). Four days after the last immunisation, spleens were removed aseptically and the splenic cells were fused, in a ratio of $8: 1$, with a non-immunoglobulin-secreting murine myeloma X63-Ag8-653, in the presence of polyethylene glycol 1450 (Sigma) 50\% v/v. Fusion; hybridoma selection and culture were performed as reported by Malavasi et al. [23]. Culture supernates were screened for antibody production by ELISA [16] with purified type IV polysaccharide as coating antigen and anti-mouse polyvalent immunoglobulins alkaline-phosphatase as conjugated antiserum (Sigma). Clones positive for antibody production were subcloned twice by limiting dilution into 96-well tissue culture plates at a concentration of 1.0 and 0.5 cell/well, expanded and kept frozen in RPMI 1640 medium (Flow) supplemented with horse serum 10\% v/v and dimethyl sulphoxide $20 \%$ v/v. A stable hybridoma (MAb H11) was selected and subsequently grown in vivo in pristane-treated $\mathrm{BALB} / \mathrm{c}$ mice. One-to-two weeks after i.p. injection of $10^{6}$ hybridoma cells, ascitic fluid was removed, clarified by centrifugation and stored at $-40^{\circ} \mathrm{C}$.

\section{Determination of specificity, immunoglobulin subclass and MAb concentration}

The specificity of the MAbs was checked by ELISA, with group B and GBS types Ia, Ib, II, III and $\mathrm{V}$ polysaccharides as coating antigens [16]. MAb isotyping was performed by ELISA [16] with both goat anti-mouse IgG ( $\gamma$-chain) and anti-mouse IgM ( $\mu$-chain) alkaline phosphatase-conjugated antiserum (Sigma). The concentration of MAb IgM in the ascitic fluids and culture supernates was determined by radial immunodiffusion (Mouse IgM NL RID Plate, The Binding Site Inc., San Diego CA, USA). The double immunodiffusion test was performed in agar as described by Ouchterlony [24].

\section{Opsonic assay}

The opsonic activity of the MAb preparation was quantified in vitro by the opsonophagocytosis killing assay [21]. Briefly, human polymorphonuclear leukocytes (PMNL) were mixed with bacteria from an exponentially growing culture in a ratio of $3: 1$, in the presence or absence of GBS-absorbed guinea pig serum $10 \% \mathrm{v} / \mathrm{v}$ as complement, and the relevant MAb (or rabbit type IV-specific antiserum) as antibody. The mixture was incubated at $37^{\circ} \mathrm{C}$ and the number of cfu was counted on Columbia blood agar at the beginning and $1 \mathrm{~h}$ after incubation. The opsonic activity was reported as the percentage decrease in the initial number of cfu. All experiments were performed in triplicate.

\section{Neuraminidase treatment}

Type IV polysaccharide was treated for $3 \mathrm{~h}$ at $37^{\circ} \mathrm{C}$ with an immobilised preparation of neuraminidase (from Clostridium perfringens; Sigma) to cleave sialic acid, as described previously [21]. After enzymic hydrolysis of the polysaccharide, the free sialic acid was assessed by high performance anion-exchange chromatography coupled with amperometric detection [21].

\section{Determination of GBS lethal dosage}

The virulence of type IV GBS was assessed by injecting bacteria i.p. or i.v. in two different animal models used in the protection experiments. The LD50 was calculated by a standard method for estimating $50 \%$ endpoint [25] and represented the mean of three separate experiments, i.p. and i.v.

i.p. route. The virulence of type IV GBS strain 1/82 by the i.p. route was assessed by injecting $10^{2}-10^{8} \mathrm{cfu} /$ mouse into groups of $10 \mathrm{CD}-1$ male mice, 4 weeks old. Mortality was recorded for 5 days. The LD50 was 3.2 $(0.1) \times 10^{6} \mathrm{cfu} /$ mouse.

i.v. route. The virulence of type IV GBS strain $1 / 82$ by the i.v. route was assessed as described previously [16]. Groups of $20 \mathrm{CD}-1$ female mice, 8-10 weeks old, were given $10^{5}-10^{9} \mathrm{cfu} /$ mouse by i.v. injection and mortality was recorded for 60 days. The LD50 was $1.94(0.15) \times 10^{7} \mathrm{cfu} /$ mouse [16]. 


\section{In-vivo protection studies}

Two murine models were used to examine the protective efficacy of MAb H11.

GBS acute infection. The protective activity of MAb H11 against lethal infection by type IV GBS was assessed in groups of eight CD-1 male mice (4 weeks old). Ascitic fluid $(0.25 \mathrm{ml})$, at different dilutions, was injected i.p. $4 \mathrm{~h}$ before or $4 \mathrm{~h}$ after lethal i.p. challenge (5 LD50 in $0.25 \mathrm{ml}$ ). Simultaneous injection of both MAb and bacteria was performed in parallel. Mortality was recorded at 24-h intervals for at least 15 days.

GBS chronic infection. The efficacy of MAb H11 against type IV GBS chronic arthritis infection was assessed with a murine model described previously by Tissi et al. [16]. Groups of $20 \mathrm{CD}-1$ female mice, 8-10 weeks old, received MAb i.v. $(0.5 \mathrm{ml}$ of ascitic fluid via the tail vein) $4 \mathrm{~h}$ before injection of $10^{7} \mathrm{cfu}(0.5 \mathrm{ml} /$ mouse $)$ of type IV GBS. In parallel, other groups of mice received the polyclonal rabbit antisera directed against type IV GBS and group B polysaccharides, with the same treatment schedule. Both the MAb and the polyclonal antibodies were used at a dilution corresponding to an ELISA titre of 6400 . The animals were observed daily for illness and death for 2 months. On days 1,5 and 10 after challenge, cultures from blood, kidneys and joints of antibody-treated or untreated mice were performed to verify group B streptococcal infection. Blood samples were obtained by retro-orbital sinus bleeding before the animals were killed. Kidneys were removed aseptically and placed in a tissue homogeniser with $3 \mathrm{ml}$ of sterile RPMI medium. Appropriate dilutions of kidneys or blood were plated in triplicate on Islam agar (Unipath) plates containing inactivated horse serum $5 \% \mathrm{v} / \mathrm{v}$ and cfu were enumerated after incubation for $48 \mathrm{~h}$ under anaerobic conditions. Results were expressed as the number of $\mathrm{cfu} / \mathrm{ml}$ of blood or whole organ. Joints were removed, ground in a mortar and resuspended in $1 \mathrm{ml}$ of sterile RPMI medium. All samples were plated on Islam agar plates and the results were expressed as the number of $\mathrm{cfu} / \mathrm{ml}$ of homogenate and as the number of positive or negative cultures from the animals examined. Control animals received an unrelated MAb (AF1, IgM antibodies against a polysaccharide epitope of Candida albicans mannoprotein) that did not react with GBS.

\section{Statistical analysis}

Differences in data of survival rates and the incidence of arthritis in the protection studies were evaluated by Fisher's exact test. Differences in the number of cfu were determined according to Student's $t$ test. Each experiment was repeated three times.

\section{Results}

\section{Production and characterisation of MAbs to GBS}

Fourteen days after immune spleen-cell fusion with myeloma cells, nine hybridoma cultures secreting IgM antibodies against the type-specific polysaccharide of type IV GBS were obtained. One of the positive cultures was selected for cloning and propagation into pristane-treated mice. A stable and high antibodyproducing clone was used as the source of the MAb (hereafter referred to as MAb H11). In ELISA, MAb H11 reacted with type IV GBS polysaccharide but not with the other type-specific or group B polysaccharides. In immunodiffusion, MAb H11 gave a single precipitin line of identity with the native type IV polysaccharide and its desialylated form (Fig. 1A); MAb H11 and rabbit hyperimmune anti-type IV serum gave a line of identity with the type IV antigen (Fig. 1B).

\section{Opsonophagocytosis assay}

The functional activity of MAb H11 was tested against viable GBS in an in-vitro neutrophil-mediated bactericidal assay (Table 1). In the presence of human neutrophils and complement, MAb H1l $(86 \mu \mathrm{g} / \mathrm{ml})$
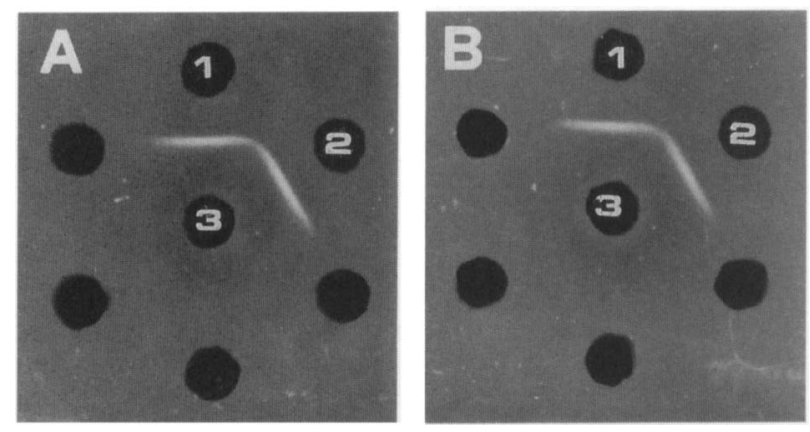

Fig. 1. A, Immunodiffusion in agar of type IV native polysaccharide (well 1) and the desialylated polysaccharide obtained after neuraminidase treatment (well 2) with MAb H11 (well 3). B, Immunodiffusion in agar of type IV native polysaccharide (well 3) with rabbit hyperimmune anti-type IV GBS (well 1) and MAb H11 (well 2).

Table 1. In-vitro opsonophagocytic killing of type IV GBS reference strain by MAb H1l in the presence of human PMNL and complement

\begin{tabular}{lccccc}
\hline & & \multicolumn{4}{c}{$\begin{array}{c}\text { Number of cfu } \\
\left(10^{6} / \mathrm{ml}\right) \text { at }\end{array}$} \\
\cline { 5 - 6 } PMNL & Complement & $\begin{array}{c}\text { MAb H11 } \\
(\mu \mathrm{g} / \mathrm{ml})\end{array}$ & 0 min & $60 \mathrm{~min}$ & $(\%)$ \\
\hline- & + & $+(86)$ & 2.4 & 3.8 & 0 \\
+ & + & - & 2.5 & 2.5 & 0 \\
+ & - & $+(86)$ & 2.9 & 3.9 & 0 \\
+ & + & $+(86)$ & 2.6 & 0.5 & 80 \\
+ & + & $+(8.6)$ & 2.6 & 2.1 & 20 \\
\hline
\end{tabular}

- absent; + present.

${ }^{*}$ Data are from a representative experiment of three performed. 
promoted $80 \%$ of killing of the GBS type IV strain, a degree of killing similar to that obtained with a rabbit IgG anti-type IV serum (diluted 1 in 100) under the same experimental conditions. No killing of type Ia, II or III GBS strains was observed (data not shown).

\section{Mouse protection studies}

Two experimental murine models of GBS infection were used to examine the protective efficacy of $\mathrm{MAb}$ $\mathrm{H} 11$ in comparison to that of the polyclonal rabbit antisera directed against the type IV and group B polysaccharides. These models were represented by mice with acute, lethal GBS infection and by mice with a chronic GBS arthritis.

Protective efficacy of MAb HII against acute lethal GBS infection. The protective efficacy of MAb $\mathrm{H} 11$ was determined in 4-week-old CD-1 mice infected i.p. with 5 LD50. MAb H11 ascitic fluid administered i.p. with the infecting bacteria, at doses of antibodies ranging from 0.3 to $1.8 \mathrm{mg} / \mathrm{kg}$ (ELISA titre, 32000 6400 ), offered significant protection against a lethal challenge with type IV GBS. Survival at the lowest dose of MAb H11 was $75 \%$, and $90 \%$ at the highest. MAb preparation was also tested for prophylactic and therapeutic activity. When administered at the highest dose $(1.8 \mathrm{mg} / \mathrm{kg}) 4 \mathrm{~h}$ before challenge with 5LD50, MAb H11 was highly protective with a $90 \%$ survival rate; when the antibody was administered $4 \mathrm{~h}$ after lethal challenge, $28 \%$ of the animals were still protected $(\mathrm{p}<0.05)$ (Fig. 2).

The protection afforded by MAb $\mathrm{H} 11$ was examined also against i.p. infection with type IV GBS clinical isolates. Of the animals given the antibody $4 \mathrm{~h}$ before infection, 80-90\% survived compared with no survival of the control animals. In contrast, no protection could be provided by anti-type IV GBS MAb H11 against lethal challenge of serotypes Ia, Ib, II, III or V (data not shown).

Protective efficacy of MAb HII against GBS chronic arthritis infection. The ability of MAb H11 to confer protection against chronic GBS infection was investigated in comparison with anti-type IV and anti-group B rabbit sera. CD-1 mice, 8-10 weeks old, were given $10^{7}$ type IV GBS by i.v. injection; this produced $40 \%$ mortality and arthritis in approximately $70 \%$ (Table 2). The administration of MAb H11 at a dose of $1.8 \mathrm{mg} / \mathrm{kg}$ (ELISA titre, 6400) offered excellent protection against both mortality and arthritis (Table 3). The hyperimmune type IV rabbit serum also reduced significantly the number of animals with

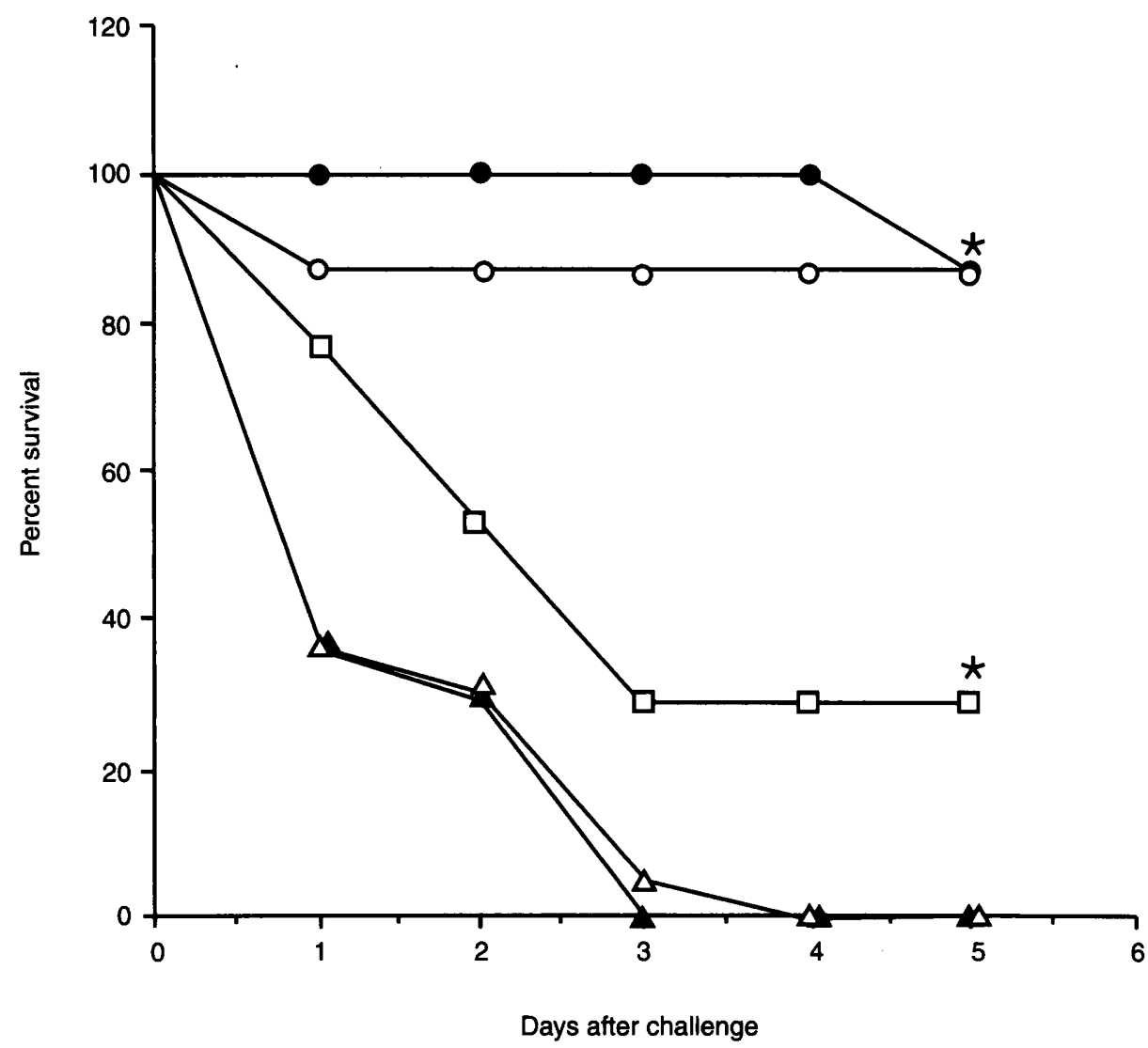

Fig. 2. Protective i.p. administration of $0.25 \mathrm{ml}$ of anti-type IV polysaccharide specific MAb $\mathrm{H} 11(1.8 \mathrm{mg} / \mathrm{kg}) 4 \mathrm{~h}$ before (O), simultaneously $(O)$ or $4 \mathrm{~h}$ after $(\square)$ i.p. inoculation of 5 LD50 $\left(1.63 \times 10^{7} \mathrm{cfu} / \mathrm{mouse}\right)$ of GBS type IV strain $1 / 82$. Control mice were treated with an unrelated MAb $(\triangle)$ and with GBS alone $(\Delta)$. Data are from three independent experiments. SE $<10 \%$ have been omitted. 
arthritis. In contrast, the anti-group B serum only slightly reduced the incidence of articular lesions (Table 2). Evaluation of cfu on day 1 after infection in the joints of animals revealed $9.2 \times 10^{1} \mathrm{cfu} / \mathrm{ml}$ of joint homogenate in mice pretreated with $\mathrm{MAb}$ against

Table 2. Effect of MAb H11, group B and type IV GBS antiserum administration on mouse survival and on incidence of arthritis induced by i.v. injection of $10^{7}$ cfu of type IV GBS, strain 1/82; the results were obtained at the end of the observation period ( 60 days $)^{*}$

\begin{tabular}{lccc}
\hline Treatment $\dagger$ & $\begin{array}{c}\text { Surviving } \\
(\%)\end{array}$ & $\begin{array}{c}\text { Mice with } \\
\text { articular lesions } \\
(\%)\end{array}$ & $\begin{array}{c}\text { Mean day } \\
\text { onset }\end{array}$ \\
\hline Control & $12(60)$ & $14(70)$ & 2 \\
MAb H11 & $20(100) \ddagger$ & $0(0) \ddagger$ & - \\
Type IV antiserum & $20(100) \ddagger$ & $3(15) \ddagger$ & 4 \\
Group B antiserum & $16(80)$ & $8(40) \S$ & 2 \\
\hline
\end{tabular}

*Values are the mean of three separate experiments. In each experiment 20 mice were used. (SE, always $<10 \%$, has been omitted.)

†Mice were pretreated by i.v. injection of $0.25 \mathrm{ml}$ of identical quantities of antibody preparations (ELISA titre 6400) $4 \mathrm{~h}$ before GBS challenge.

$\ddagger \mathrm{p}<0.001$ (treated mice versus control)

$\S \mathrm{p}<0.05$ (treated mice versus control).
$1.9 \times 10^{6} \mathrm{cfu} / \mathrm{ml}$ of joint homogenate in controls (Table 3). In MAb H11-treated mice, bacteria were completely cleared, as demonstrated by the absence of positive mice on day 5 (Table 3). The number of bacteria found after pretreatment with type IV antiserum or anti-group B serum on day 1 was lower than in controls $(p<0.001)$, but higher than in MAbtreated animals.

As chronic systemic GBS infection in adult mice is characterised by the presence of high numbers of live bacteria in kidneys [16], cfu enumeration in blood and kidneys at different times after protective treatment with MAb, type- or group-specific antisera was also performed. Whereas all the treated animals cleared the organisms from the blood within 5 days, control mice had the first negative blood culture only on day 10 (Table 4). Kidneys of all mice were colonised by GBS at each examination but in the controls and in the anti-group B serum-treated mice, cfu strongly increased during the first 10 days of infection. In contrast, in MAb H11- and type IV antiserum-treated mice, the numbers of cfu decreased significantly in the same period.

Table 3. Growth of type IV GBS in the joints of CD1 mice pretreated with MAb H11, group B- or type IV-specific antiserum on days 1, 5 and 10 post-infection

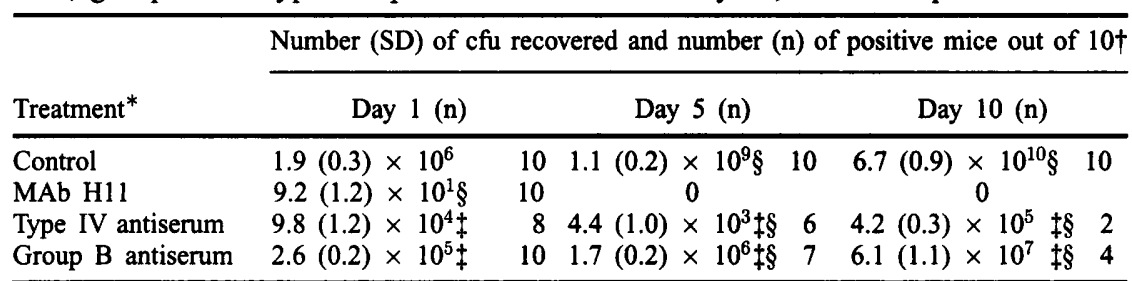

${ }^{*}$ All pretreatments were performed $4 \mathrm{~h}$ before GBS infection with $10^{7} \mathrm{cfu} / \mathrm{mouse}$.

†Ten mice/group were killed at each time point. The numbers of $\mathrm{cfu} / \mathrm{ml}$ of joint homogenate are reported. Values are an average of three independent experiments.

$\ddagger$ Values significantly different from control $(\mathrm{p}<0.001)$.

$\S$ Values significantly different from day $1(\mathrm{p}<0.001)$

Table 4. Growth of type IV GBS in blood and kidneys of CD-1 mice pretreated with MAb H11, group B- or type IVGBS specific antiserum*

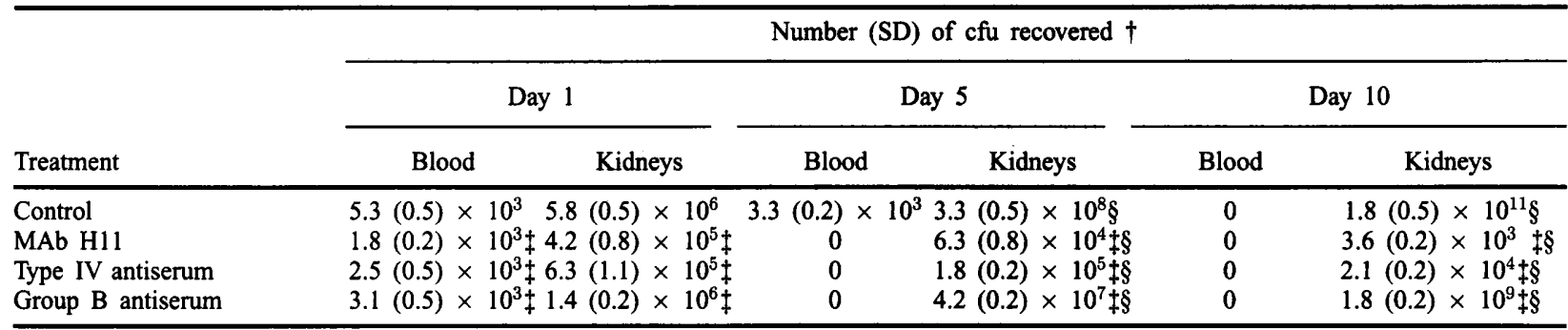

${ }^{*}$ Mice were pretreated i.v. with $0.25 \mathrm{ml}$ of identical quantities of antibody preparation (ELISA titre 6,400$) 4 \mathrm{~h}$ before GBS challenge (10 ${ }^{7}$ cfu mouse).

†Eight mice/group were killed at each time point. The number of cfu/ml of blood or for both kidneys are reported. Values are an average of three independent experiments.

‡Values significantly different from controls $(p<0.001)$.

$\S$ Values significantly different from day $1(\mathrm{p}<0.001)$. 


\section{Discussion}

The present study demonstrated that a murine monoclonal IgM antibody (MAb H11) to type IV antigen is protective in mouse models of acute and chronic type IV group B streptococcal infections. MAb H11 was specific for both sialylated and desialylated type IV polysaccharide. This finding confirms that sialic acid does not influence the expression of the native immunodeterminant type IV polysaccharide [19]. In fact, the two forms of type IV antigen gave a reaction of identity in immunodiffusion both with the MAb and the polyclonal rabbit anti-type IV GBS serum. It was not possible to obtain anti-polysaccharide antibody isotypes other than IgM. On the other hand, the majority of the described MAbs against GBS type polysaccharides (Ia, Ib, II and III) belong to the IgM class and only a few to the IgG class $[10,14]$.

The MAb was protective in acute infections only when given simultaneously or before challenge. The role of type-specific antibodies in the prevention of acute infection has been suggested by Lancefield et al. [26], who demonstrated that various mouse protective antibodies can be produced in the sera of experimentally immunised rabbits. Furthermore, low levels of maternal type-specific antibodies are shown to increase the risk of neonatal infections on man [5]. Infants transfused with blood containing opsonic antibody against the infecting serotype of GBS are more likely to survive than those transfused with blood without antibody to the infecting organism [27]. These results indicate a key role for type-specific antibodies in the first stages of infection, probably by facilitating phagocytosis and killing by PMNL. Furthermore, to be effective, the protective treatment should begin very early, because antibodies cannot overcome active bacterial multiplication. MAb H11 was able to prevent the establishment of chronic septic arthritis. This is particularly important as septic arthritis is a serious clinical manifestation associated with GBS infection not only in infants, but also in adults $[1,3,28]$. Furthermore, the early administration of $\mathrm{MAb} \mathrm{H} 11$, or type-specific serum, significantly reduced infection in kidneys and completely cleared GBS from blood from day 5. The isotype difference between the antibodies of the rabbit anti-type IV serum (IgG class) and the MAb H11 preparation (IgM) might account for the higher protective activity of the MAb. Similar results on the protective activity of antibodies have been observed by Raff et al. [29], who reported that more effective protection against the virulent strain type III GBS was obtained with human IgM MAb than with a genetically engineered IgG with the same antigen combining regions.

In conclusion, the present results demonstrate that the effective neutralisation of the capsular type-specific polysaccharide is important in protection against both acute or chronic GBS infection. The presence of antibodies in the early stages of GBS infection reduces the lethality of the disease, as well as kidney and joint colonisation.

This work was supported in part by the CNR Target Project on Biotechnology and Bioinstrumentation, grant no. 89.00262.70. We thank Eileen Zannetti for editorial and secretarial assistance.

\section{References}

1. Baker CJ, Edwards MS. Group B streptococcal infections. In: Remington JS, Klein JO (eds) Infectious diseases of the fetus and newborn infant. Philadelphia, WB Saunders Company. 1983: 820-881.

2. Eykyn SJ, Young SEJ, Cookson BD. Increased communityacquired septicaemic infection with group B streptococci in adults. Lancet 1991; 338: 446

3. Farley MM, Harvey RC, Stull $\mathrm{T}$ et al. A population-based assessment of invasive disease due to group B Streptococcus in nonpregnant adults. $N$ Engl $J$ Med 1993; 328: 1807-1811.

4. Rubens CE, Wessels MR, Heggen LM, Kasper DL. Transposon mutagenesis of type III group B Streptococcus: correlation of capsule expression with virulence. Proc Natl Acad Sci USA 1987; 84: 7208-7212.

5. Baker CJ, Kasper DL. Correlation of maternal antibody deficiency with susceptibility to neonatal group B streptococcal infection. $N$ Engl J Med 1976; 294: 753-756.

6. Fischer GW, Weisman LE, Hemming VG. Directed immune globulin for the prevention or treatment of neonatal group B streptococcal infections: a review. Clin Immunol Immunopathol 1992; 62: S92-S97.

7. Fischer GW, Weisman LB, Hemming VG et al. Intravenous immunoglobulin in neonatal group B streptococcal disease. Pharmacokinetic and safety studies in monkeys and humans. Am $J$ Med 1984; 76: S117-S123.

8. Kim KS, Wass CA, Kang JH, Anthony BF. Functional activities of various preparations of human intravenous immunoglobulin against type III group B Streptococcus. J Infect Dis 1986; 153: 1092-1097.

9. Weisman LE, Anthony BF, Hemming VG, Fischer GW. Comparison of group B streptococcal hyperimmune globulin and standard intravenously administered immune globulin in neonates. J Pediatr 1993; 122: 929-937.

10. Egan ML, Pritchard DG, Dillon HC, Gray BM. Protection of mice from experimental infection with type III group B Streptococcus using monoclonal antibodies. J Exp Med 1983; 158: $1006-1011$.

11. Shigeoka AO, Pincus SH, Rote NS, Hill HR. Protective efficacy of hybridoma type-specific antibody against experimental infection with group-B Streptococcus. $J$ Infect Dis 1984; 149: 363-372.

12. Gray BM, Egan ML, Pritchard DG. Specificity of monoclonal antibodies against group B Streptococcus type II and inhibition of their binding by human secretions. Pediatr Res 1988; 24: $68-72$.

13. Raff HV, Siscoe PJ, Wolff EA, Maloney G, Shuford W. Human monoclonal antibodies to group B Streptococcus. Reactivity and in vivo protection against multiple serotypes. $J$ Exp Med 1988; 168: 905-917.

14. Teti G, Calapai M, Calogero G et al. Specificity and protective activity of murine monoclonal antibodies directed against the capsular polysaccharide of type III group B streptococci. Hybridoma 1992; 11: 13-22.

15. Hill HR, Kelsey DK, Gonzales LA, Raff HV. Monoclonal antibodies in the therapy of experimental neonatal group B streptococcal disease. Clin Immunol Immunopathol 1992; 62 : S87-S91.

16. Tissi L, Marconi $\mathrm{P}$, Mosci $\mathrm{P}$ et al. Experimental model of type IV Streptococcus agalactiae (Group B Streptococcus) infection in mice with early development of septic arthritis. Infect Immun 1990; 58: 3093-3100.

17. Rabinowitz S, Ferne M, Halfon ST. Group B streptococci: different serotypes associated with clinical infection. Lab Pract 1980; 29: 733-734.

18. Jelinková J, Motlová J. Worldwide distribution of two new serotypes of group B streptococci: type IV and provisional type 
V. J Clin Microbiol 1985; 21: 361-362.

19. Wessels MR, Benedí VJ, Jennings HJ, Michon F, DiFabio JL, Kasper DL. Isolation and characterization of type IV group B Streptococcus capsular polysaccharide. Infect Immun 1989; 57 : 1089-1094.

20. Molinari A, von Hunolstein C, Donelli G, Paradisi S, Arancia G, Orefici G. Effects of some capsular components on pathogenicity of type IV and provisional type V group B streptococci. FEMS Microbiol Lett 1987; 41: 69-72.

21. von Hunolstein C, D'ascenzi S, Wagner B et al. Immunochemistry of capsular type polysaccharide and virulence properties of type VI Streptococcus agalactiae (Group B streptococci). Infect Immun 1993; 61: 1272-1280.

22. Lancefield RC. A serological differentiation of specific types of bovine hemolytic streptococci (group B). J Exp Med 1934; 59: 441-458.

23. Malavasi F, Caligaris-Cappio F, Milanese C, Dellabona P, Richiardi P, Carbonara AO. Characterization of a murine monoclonal antibody specific for human early lymphohemapoietic cells. Human Immunol 1984; 9: 9-20.

24. Ouchterlony O. Diffusion-in-gel methods for immunological analysis. Prog Allergy 1958; 5: 1-78.

25. Reed L, Muench H. A simple method of estimating fifty per cent endpoints. Am J Hyg 1938; 27:493-397.

26. Lancefield RC, McCarty M, Everly WN. Multiple mouseprotective antibodies directed against group B streptococci. $J$ Exp Med 1975; 142: 165-179.

27. Shigeoka AO, Hall RT, Hill HR. Blood-transfusion in group-B streptococcal sepsis. Lancet 1978; 1: 636-638.

28. Butkus Small C, Slater LN, Lowry FD, Small RD, Salvati EA, Casey JI. Group B streptococcal arthritis in adults. Am J Med 1984; 76: 367-375.

29. Raff HV, Bradley C, Brady W et al. Comparison of functional activities between IgG1 and IgM class-switched human monoclonal antibodies reactive with group B streptococci or Escherichia coli K1. J Infect Dis 1991; 163: 346-354. 